\title{
Impact of COVID-19 on Food Systems and Rural Livelihoods in Kenya
}

\author{
COVID-19 Country Report 2 - December 2020 Prepared by John Olwande and Miltone Ayieko
}

\section{Introduction}

Since 12 March 2020, when Kenya reported the first COVID-19 cases, the Ministry of Health confirmed a total of 45,076 cases and 839 deaths, as of 19 October. ${ }^{1}$ Despite the rising number of COVID-19 confirmed infections and deaths in Kenya during the third quarter (Q3) of 2020, the national and county governments relaxed some of the restrictions that had been in place during Q2 aimed at controlling the spread of COVID-19. This assessment was aimed at understanding the effects of COVID-19 at household level and attendant policy responses during Q3 of 2020, to inform actions to assure protection of local food systems, rural livelihoods and the supply of adequate, affordable food of acceptable quality to the population.

\section{Context}

The assessment was conducted through a rural household survey of a stratified random sample of 96 smallholder agricultural households (34 female-; 66 male-headed) in Kiambu, Kilifi, Kwale, Muranga and Nakuru counties. The sample was obtained from the Tegemeo Agricultural Policy Research and Analysis household survey conducted in 2014, which had a sample size of 7,000 households in 38 counties. This survey was conducted between 5-14 October 2020 and is the second round (R2) of three surveys on the same sample of households to assess the effect of COVID-19 on food systems and rural livelihoods.

\section{Health and disease}

About $17 \%$ of respondents had heard about a confirmed case of COVID-19 infection in their village or sub-county, while one reported an incidence of infection in the household. These figures were much higher than reported during R1, which were $9 \%$ and $0 \%$, respectively. Respondents also reported increased care for the sick and elderly (20\%), children (52\%) and other family members (26\%), and an increase in the burden for household chores (50\%). These proportions suggest the burden of COVID-19 is falling on women, as they are the ones that mostly perform the care responsibilities and household chores.

\section{Farming, labour and marketing}

Approximately 27\% of respondents reported that they or their spouse had decreased participation in farming due to COVID-19, similar to findings during R1. About $46 \%$ were unable to hire labour for their farm and their business activities. Wage rate for seasonal work remained largely unaffected, while an increase in the daily wage rate for rural labour was reported by $46 \%$ of respondents. This is different from R1, when daily wage rate was reported to have largely remained unchanged. Over $43 \%$ of respondents reported a decrease in their ability to

\section{Key findings}

- Approximately $17 \%$ of respondents had heard about at least one confirmed case of COVID-19 in their village or sub-county, and one reported that a household member had been infected. These figures are higher than reported during Q2 in June.

- Similar to R1, approximately $27 \%$ of respondents reported that they or their spouse had scaled down participation in farming due to COVID-19.

- About $46 \%$ of respondents could not hire farm labour, while a similar percentage reported an increase in the daily wage rate, which was largely unchanged from Q2.

- Rural people have increased movement in and out of villages and interactions with people from outside following relaxation of policy restrictions in Q3.

- Normal agricultural trading in villages and local markets had not fully resumed.

- Availability of key agricultural inputs and production services improved during Q3 compared to Q2, but nearly half $(48 \%)$ of respondents reported increased prices for these inputs.

- A substantial proportion of respondents reported reduced availability of fruits (55\%), pulses, nuts, and seeds (54\%), and white roots and tubers (48\%) in local markets, while over $61 \%$ reported price increases for these foods; largely unchanged compared to R1.

- $\quad 77 \%$ of households did not have adequate food to meet family needs, down from $89 \%$ recorded during $\mathrm{R} 1$.

sell produce at the farm gate and in local markets, while $63 \%$ reported a decrease in the number of traders/brokers that came to their villages. This indicates that normal trading of agricultural produce in villages and local markets has not resumed, despite the government's relaxation of some of the restrictive policy measures aimed at controlling the spread of COVID-19.

"Since several restrictions due to COVID-19 were relaxed, people have generally become less cautious and employment of labour on farms is picking up. The only challenge is that farmers do not have money to employ much labour because the general economic situation has not stabilised" - Agricultural officer, Nakuru County 


\section{Availability of services for food production}

Just over $27 \%$ of respondents reported a decrease in the availability of key agricultural inputs, while $54 \%$ reported no change. Increase in input prices was reported by $48 \%$ of respondents. A substantially high number of respondents also reported a decrease in availability of agricultural extension services (55\%), credit (56\%) and concessionary loans/loan 'holidays' (32\%). Except for credit, these proportions suggest improvement compared to R1.

\section{Food and nutrition security}

A substantial proportion of respondents reported reduced availability of fruits (55\%), pulses, nuts, and seeds (54\%), and white roots and tubers (48\%) in local markets (Fig 1). Respondents also reported reduction in availability of other foods products - grains, eggs, vegetables, milk, fish, meats and processed foods; $61 \%$ reported price increases for fruits, pulses, nuts, seeds, and white roots and tubers, while $30-49 \%$ reported price increases for other foods, except processed food for which only $23 \%$ of respondents reported an increase in prices. About $77 \%$ of households, up from $89 \%$ in R1, did not have adequate food to meet family needs (Table 1).

Figure 1: Changes in availability of foods in local markets

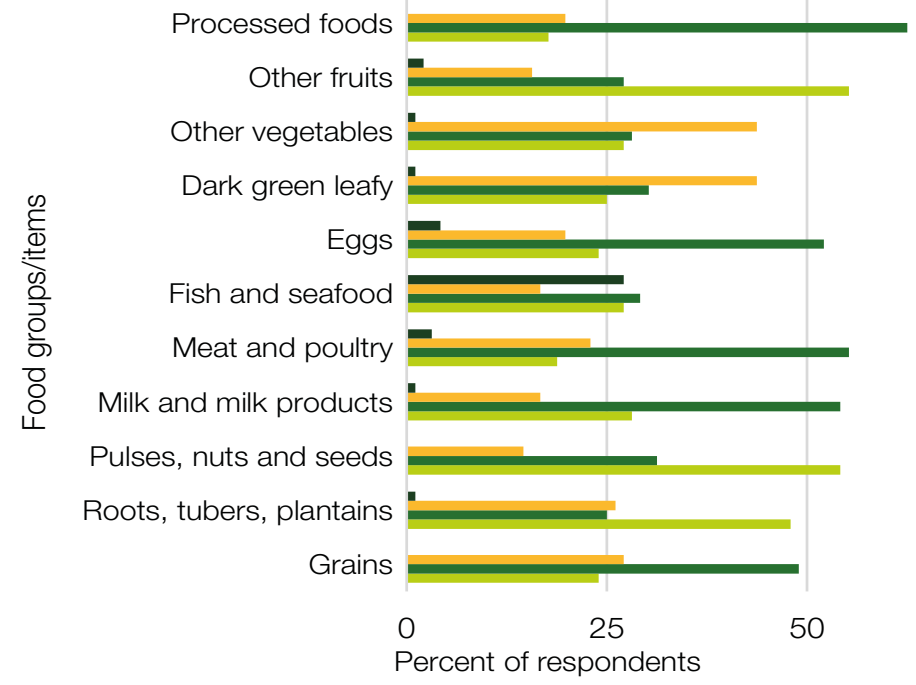

- Not applicable

$$
\text { Percent of respondents }
$$

Increase No change
Table 1: Food Insecurity Experience Scale (FIES)

\begin{tabular}{|l|c|}
\hline Experience & Respondents \\
\hline Worried about inadequate food & $83 \%$ \\
\hline Unable to eat healthy foods & $80 \%$ \\
\hline Ate only a few food types & $83 \%$ \\
\hline Skipped meals & $70 \%$ \\
\hline Ate less & $78 \%$ \\
\hline Ran out of food & $56 \%$ \\
\hline Hungry but no food to eat & $55 \%$ \\
\hline No eating for the whole day & $40 \%$ \\
\hline Food not adequate for family & $77 \%$ \\
\hline
\end{tabular}

\section{Responses to the threat of COVID-19}

Kenya established a broad range of measures and guidelines to control the spread of COVID-19 and mitigate the potential effects of both the pandemic and the measures. About $97 \%$ of respondents stated that they were observing the guidelines to control the spread of COVID-19. Respondents also reported reduced movement within the village (76\%), reduced movement outside the village $(75 \%)$ and limited visits by/to relatives (28\%). Nearly $67 \%$ observed a decrease in the number of traders/brokers coming to their villages. These proportions are much lower compared to those in R1, indicating that the government's reduction of restrictions in movement and gatherings is already altering the behaviour of people regarding their mobility and physical interactions.

Olwande, J. (2020) Impact of COVID-19 on Food Systems and Rural Livelihoods in Kenya. Round 2 - December 2020, APRA COVID-19 Country Report, Brighton: Future Agricultures Consortium

\section{APRA 2020 \\ ISBN: 978-1-78118-739-5 \\ DOI: $10.19088 / A P R A .2020 .017$}

This is an Open Access report distributed under the terms of the Creative Commons Attribution Non Commercial No Derivatives 4.0 International licence (CC BY-NC-ND), which permits use and distribution in any medium, provided the original authors and source are credited, the work is not used for commercial purposes, and no modifications or adaptations are made.

If you use the work, we ask that you reference the APRA website (www.future-agricultures.org/apra) and send a copy of the work or a link to its use online to the following address for our archive: APRA, Future Agricultures, University of Sussex, Brighton BN1 9RE, UK (apra@ids.ac.uk) 